\title{
Breeding Habitat Distribution of Medically Important Mosquitoes in Kurunegala, Gampaha, Kegalle, and Kandy Districts of Sri Lanka and Potential Risk for Disease Transmission: A Cross-Sectional Study
}

\author{
Koshila Ranasinghe, ${ }^{1}$ Nayana Gunathilaka $\left(\mathbb{D},{ }^{2}\right.$ Deepika Amarasinghe ${ }^{D}$, 1 \\ and Lahiru Udayanga ${ }^{3}$ \\ ${ }^{1}$ Department of Zoology and Environmental Management, Faculty of Science, University of Kelaniya, Ragama, Sri Lanka \\ ${ }^{2}$ Department of Parasitology, Faculty of Medicine, University of Kelaniya, Ragama, Sri Lanka \\ ${ }^{3}$ Department of Biosystems Engineering, Faculty of Agriculture \& Plantation Management, Wayamba University of Sri Lanka, \\ Makadura, Sri Lanka \\ Correspondence should be addressed to Nayana Gunathilaka; n.gunathilaka@kln.ac.lk
}

Received 4 April 2020; Accepted 20 August 2020; Published 2 September 2020

Academic Editor: Aditya Prasad Dash

Copyright (c) 2020 Koshila Ranasinghe et al. This is an open access article distributed under the Creative Commons Attribution License, which permits unrestricted use, distribution, and reproduction in any medium, provided the original work is properly cited.

\begin{abstract}
Some arbovirus infections, especially dengue, have increased rapidly over the last few decades in Sri Lanka. Prevalence and distribution of different mosquito species have been limitedly documented, which remains grossly inadequate in providing evidence for potential health risks. In this study, the diversity and species composition of mosquitoes in four selected districts in Sri Lanka (Kurunegala, Gampaha, Kegalle, and Kandy) were investigated. Entomological surveys were conducted from a total of 160 temporary and permanent mosquito breeding habitats identified in the study area from June 2017 to October 2018. Mosquito immature stages were sampled using standard dipping, siphoning, or pipetting methods and identified up to the species level. Percentage relative abundance and habitat characteristics such as species richness, dominance, and Shannon-Weiner diversity were calculated for each surveyed habitat type. Associations between co-occurring species were estimated by Hulbert's coefficient of interspecific association (C8). A total of 4663 mosquito larvae belonging to seven genera and fifteen species of mosquitoes were collected. The relative distribution of mosquito species differed significantly among the four studied districts $\left(X^{2}=143.248 ; d f=33 ; P<0.001\right)$. According to Kruskal-Wallis statistics $(P<0.05$ at $95 \%$ of significance $)$, all diversity indices for immature stages of medically important mosquitoes varied significantly across different breeding sites. Paddy fields had the significantly highest species richness of $4.0 \pm 2.82$. The coefficients of interspecific association among all the recorded medically important vector mosquitoes were found negative during the present study. The findings of the current study would be useful to identify the entomological potential for disease transmission and facilitate the implementation of appropriate vector control interventions. This would ultimately provide an avenue to improve the personal skills of health staff rather than limiting their knowledge to specified disease vectors, under which the control program is concerned.
\end{abstract}

\section{Introduction}

Vector-borne diseases have emerged as a serious public health concern, especially in tropical countries including Sri Lanka. Not surprisingly, arboviruses have caused vast epidemics with impressive numbers of patients or deaths. Sri Lanka has been suffering from mosquito-borne diseases since ancient times with the high prevalence of malaria, filariasis, and Japanese encephalitis (JE) [1]. A total of 159 species of mosquitoes under 19 genera have been recorded in Sri Lanka [2].

At present, dengue has grown up to a regular endemic and an important public health problem in Sri Lanka with 
over 40,000 cases reported annually [3]. Growing populations of vector mosquitoes due to unplanned urbanization, industrialization, and excessive population growth coupled with rural to urban migration have been identified as the major reasons for elevated dengue incidence in many countries including Sri Lanka [4]. Many mosquito species tend to select both natural and artificial containers as their breeding places [5]. They exploit almost all types of lentic aquatic habitats for their breeding [6].On the other hand, rice fields and marshy land habitats in Sri Lanka have significantly influenced the distribution of mosquito populations, including vector mosquitoes, thereby facilitating disease transmission [7]. Mainly larvae of Culex and Anopheles species are found in rice fields, nursery paddy beds, and large stagnant water bodies in Sri Lanka [8]. Ecological factors and physicochemical properties of water in the breeding habitat significantly affect the mosquito density and abundance [9]. The size, type, and nature of water body are found to be influensive in selecting the oviposition sites by mosquitoes [10].

Controlling immature stages of vector mosquitoes in their aquatic habitats is considered as the most effective mosquito controlling strategy [11]. Although vector control strategies have traditionally focused on killing mosquitoes using a variety of synthetic chemical insecticides, the development of insecticide resistance has declined the efficiency of killing mosquitoes. Also, the financial burden of insecticide-based vector control programs is a limiting factor for appropriate usage of larvicides and adulticides in many countries where mosquito-borne diseases remain endemic [12]. Therefore, an investigation of the prevalence and distribution of these mosquito immature stages may facilitate a better understanding of the distribution of different mosquito species.

Knowledge on where mosquitoes breed, their habitat preference over others, and the larval distribution are important parameters for risk assessment and implementation of sound mosquito control strategies. At present, dengue vectors have received a wider attention in Sri Lanka due to the rapid increase of dengue incidence [13]. However, there is a scarcity and scattered information about the mosquito fauna recorded from breeding habitats. The prevalence of different mosquito species from surveillance has been limitedly documented in Sri Lanka in recent years, which is grossly inadequate in providing evidence for potential health risks. The present investigation attempts to cater to this knowledge gap by documenting the prevalence of mosquito species in four selected districts of Sri Lanka.

\section{Methods}

2.1. Study Area. Four districts of Sri Lanka, namely Gampaha (Western Province), Kandy (Central province), Kegalle (Sabaragamuwa Province), and Kurunegala (Northwestern Province), representing climatically different regions, were selected for the study. The average climatological parameters of the study areas are indicated in Table 1.
2.2. Selection of Breeding Habitats and Entomological Investigations. A preliminary survey was conducted from April to May 2017 to select districts and all possible sites conducive for mosquito breeding. A checklist of breeding habitats was prepared for all the study areas, including both permanent and temporary breeding habitats. Entomological surveys were conducted on a monthly basis from June 2017 to October 2018 at identified sampling locations (Figure 1), using standard dipping, siphoning, and pipetting methods according to the nature of the breeding habitat [14].

The location of the temporary or permanent breeding habitats was recorded using a portable global positioning (GARMIN eTrex SUMMIT) receiver. Collected mosquito larvae from 160 sampling sites were safely transported to the laboratory at the Department of Zoology and Environmental Management, University of Kelaniya, Sri Lanka.

2.3. Identification of Field-Caught Specimens. The fieldcaught larvae were first separated to the genus level and classified into instar stages (I, II, III, and IV). Larval stages III and IV were used for species identification directly. Other stages were reared at the insectary until reach to the stage III for species identification. Pupae were reared under insectary conditions, and adults emerged were processed for identification. Morphological keys were used to confirm the species identification [15-18].

2.4. Data Interpretation and Statistical Analysis. The percentage relative abundance of each species of mosquito immature stages was calculated. Habitat characteristics such as species richness, dominance, and Shannon-Weiner diversity were calculated for each habitat type. Distance-based redundancy analysis (dbRDA) was used to identify spatial similarities in mosquito community assemblages at the district level. Associations between co-occurring species were estimated by Hulbert's coefficient of interspecific association (C8) using presence-absence data as recommended by Hurlbert, 1969 [19]. Values for C8 could range from -1 to +1 for negative and positive associations, respectively. The formula used for calculating $\mathrm{C} 8$ is as follows:

$$
\mathrm{C} 8=\frac{\mathrm{ad}-\mathrm{bc}}{|\mathrm{ad}-\mathrm{bc}|} \sqrt{\frac{\mathrm{Obs}_{x^{2}}-\operatorname{Min}_{x^{2}}}{\operatorname{Max}_{x^{2}}-\operatorname{Min}_{x^{2}}}},
$$

where $a, b, c$, and $d$ are the values in four cells of a $2 \times 2$ contingency table; Obs $\chi^{2}$ is referred to the value of $\chi^{2}$ associated with the observed values of a, b, c, and d; $\operatorname{Max} \chi^{2}$ is referred to the value of $\chi^{2}$ when a is as large (if $\mathrm{ad} \geq \mathrm{bc}$ ) or as small (if $\mathrm{ad}<\mathrm{bc}$ ) as the marginal totals of the $2 \times 2$ table permit; and Min $\chi^{2}$ is referred to the value of $\chi^{2}$ when the observed a differs from its expected value (a) by less than 1.00 .

The chi-squared test of independence was used to evaluate the significance in the distribution of different mosquito species among different breeding sites and districts. The calculated diversity indices were subjected to the Kruskal-Wallis test followed by Dunn's multiple comparison (with Bonferroni adjustment) to identify the significance 
TABLE 1: Ecological characteristics of the study areas.

\begin{tabular}{|c|c|c|c|c|}
\hline \multirow{2}{*}{ Factor } & \multicolumn{4}{|c|}{ District } \\
\hline & Kurunegala & Gampaha & Kegalle & Kandy \\
\hline Climatic zone & Intermediate & Wet & Wet & Wet \\
\hline Average annual temperature $\left({ }^{\circ} \mathrm{C}\right)$ & 27.3 (rise up to $35^{\circ} \mathrm{C}$ in April) & 27.3 & 26.3 & 24.5 \\
\hline Temperature range $\left({ }^{\circ} \mathrm{C}\right)$ & $25-32.5$ & $25-32.5$ & $25-30$ & $17.5-25$ \\
\hline Annual mean rainfall $(\mathrm{mm})$ & 1993 & 2398 & 2493 & 2083 \\
\hline Rainfall range $(\mathrm{mm})$ & $1000-2000$ & $2000-3500$ & $2000-3500$ & $2000-6000$ \\
\hline
\end{tabular}

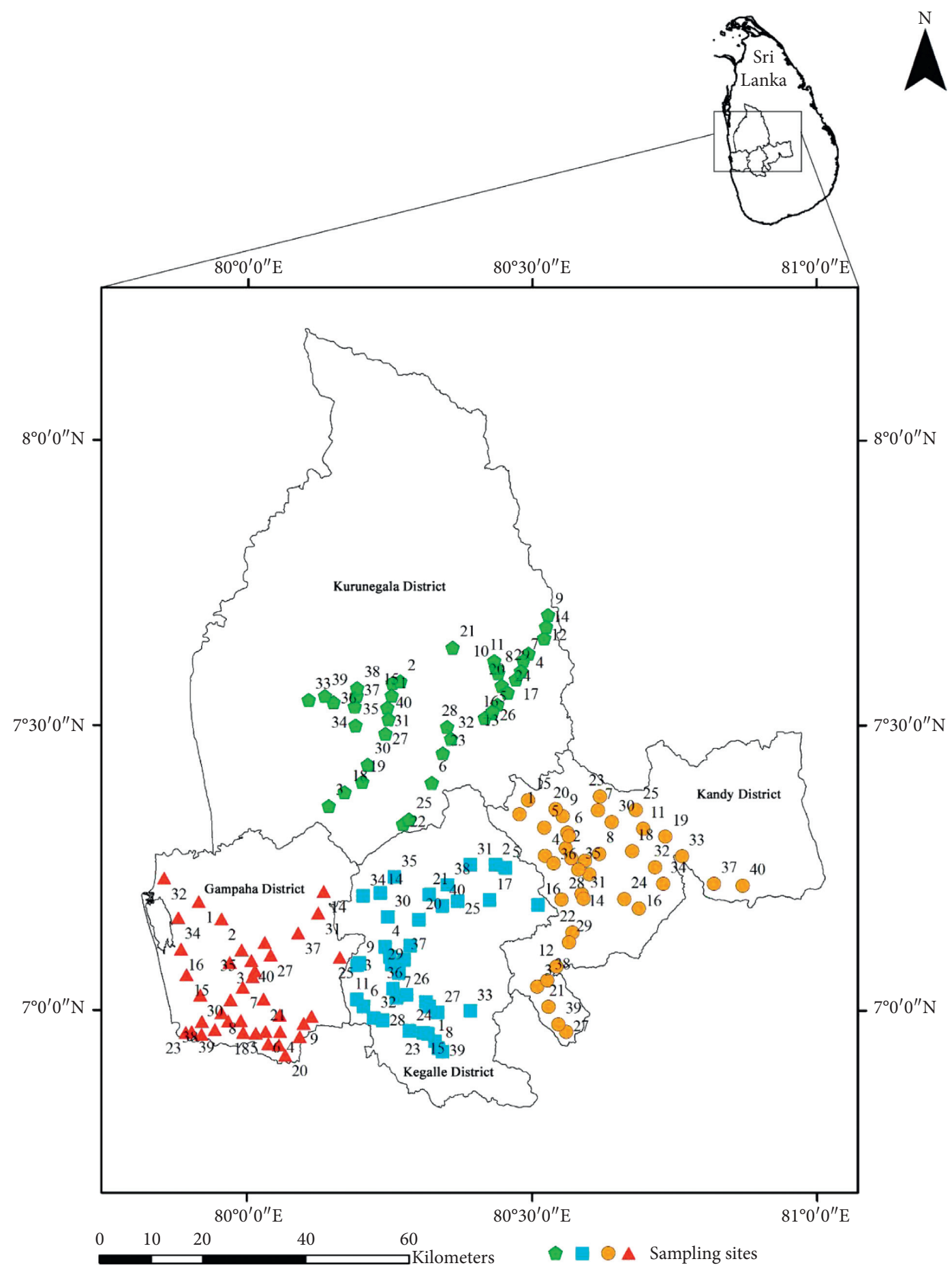

FIGURE 1: Sampling locations from the selected four district study sites: Kurunegala, Gampaha, Kegalle, and Kandy, Sri Lanka. 
in the variations of diversity indices across breeding sites and the districts.

\section{Results}

3.1. Species Composition. A total of 4663 mosquito larvae belonging to fifteen species under seven genera were collected from natural and artificial water-holding macro- and microhabitats located in study sites during the sampling period (Table 2). The highest number of mosquito immature stages $(n=1554)$ were collected from Kurunegala district. Culex species were dominant in all the four districts followed by Aedes mosquitoes. Culex gelidus (26.45\%) was the most predominant mosquito species in Kurunegala followed by Cx. tritaeniorynchus (25.35\%). Aedes albopictus was the most abundant species in Gampaha and Kandy districts, accounting for $26.39 \%$ and $36.65 \%$, respectively. Meanwhile, Ae. aegypti (19.19\%) dominated in Kegalle district (Supplementary Annexure 1). Statistics of the chi-squared test of independence $\left(X^{2}=117.904 ; d f=3 ; P<0.001\right)$ indicated that the distribution of both Ae. aegypti and Ae albopictus differed significantly among the studied districts at 95\% level of confidence. The highest abundance of Aedes vectors was recorded from Kandy (46.95\%) and Gampaha (41.28\%) districts, which were among the high-risk areas recently for dengue within the country $[19,20]$.

3.2. Distance-Based Redundancy Analysis (dbRDA) for the Distribution Pattern of Mosquito Species. The relative distribution of different mosquito species differed significantly among the four districts $\left(X^{2}=143.248 ; d f=33 ; P<0.001\right)$. Mosquito assemblages in Gampaha and Kandy districts indicated a similarity of $83.16 \%$, while Kegalle district shared a similarity of $75.45 \%$ with the above cluster. On the other hand, Kurunegala shared only $69.99 \%$ similarity with the other two clusters, forming three subclusters based on the Bray-Curtis similarity (Figure 2). According to the loadings of the dbRDA axes, relatively higher densities of $A n$. subpictus, Cx. gelidus, and Cx. tritaeniorynchus could be recognized as the reasons for the separation of Kurunegala district as a separate cluster, while a higher abundance of $A e$. aegypti and Armigeres subalbatus could be recognized as the characteristic features of Kegalle district. The dominance of Ae. albopictus over Ae. aegypti and higher densities of $C x$. tritaeniorynchus and Tripteroides sp. can be identified as the factors for the separation of Gampaha and Kandy districts as a single cluster (Figure 2).

3.3. Habitat Positivity. A total of 21 permanent/temporary key breeding sites were found from the study areas (Table 3). Paddy fields and Marshy lands were found in all four districts as permanent mosquito breeding habitats. The majority of the sampled breeding habitats belonged to the category of temporary microbreeding habitats (Figure 3). Five major macrobreeding habitat types, such as marshy lands, paddy fields, ponds, reservoirs, and tank margins, were positive for immature stages, while the highest larval diversity and abundance were found in paddy fields $(n=1399)$. The majority of species recorded from there belonged to the genus Culex. Anopheles larvae were only recorded from the tank margins and stagnant water bodies (Figure 4(a)). A higher proportion of temporary microbreeding habitats was occupied by Ae. aegypti and Ae. albopictus immature stages (Figure 4(b)), while Ae. albopictus showed a relatively higher distribution and abundance over Ae. aegypti.

Out of fifteen mosquito species recorded from the study area, ten species were medically important. Among them, Ae. albopictus exhibited the highest habitat diversity selection for breeding (Table 4). Majority of the breeding sites of Ae. aegypti and Ae. albopictus mosquitoes were temporary containers. Other than discarded container habitats, Ae. aegypti immature stages were found in water collected in fallen dried leaves, whereas Ae. albopictus larval stages were found from tree holes, stream margins, and abandoned and dried up wells and ponds. Only two species of Anopheles were recorded in the present study, and both species are medically important. About $73.3 \%$ of total Cx. tritaeniorynchus larvae collected were found in paddy fields.

\subsection{Diversity of Mosquito Larvae within Breeding Habitats.} As suggested by the Kruskal-Wallis statistics $(P<0.05$ at $95 \%$ of significance), all the diversity indices for immature stages of medically important mosquitoes varied significantly across different breeding sites during the study $(k=20)$. Meanwhile, none of the diversity indices indicated significant differences in terms of locality (studied districts). Paddy fields had the highest species richness of $4.0 \pm 2.82$. Among all 21 different types of breeding sites recorded, the highest Shannon-Weiner diversity was observed from paddy fields $(7.06 \pm 2.82)$, while 14 breeding sites denoted a null Shannon-Weiner diversity, due to the presence of a single mosquito species (Table 5). The highest values of Pielou's index (2.01 \pm 0.6$)$, Menhinik's index (3.34 \pm 0.83$)$, and Margalef's index $(0.59 \pm 0.19)$ in terms of medically important mosquito larvae were also shown by paddy fields.

3.5. Interspecific Association of the Common Species. The coefficients of interspecific association among all the recorded medically important vector mosquitoes were negative. The lowest coefficient value remained as -0.05 . Ae. aegypti, Ar. subalbatus, and Mansonia uniformis denoted the strongest negative coefficients of interspecific association $(-0.13)$ for all the vector species. Therefore, different habitat preferences or interspecific repulsions among the reported vector stages are revealed by the negative associations between species.

\section{Discussion}

As a result of successive efforts in control programs, Sri Lanka has received remarkable achievements by receiving the WHO certification as malaria-free in 2016 and filariasis as no longer a public health concern [21]. However, despite all the successful efforts, some arbovirus infections (especially dengue) have increased rapidly over the last few 
TAвLE 2: The abundance of mosquito species in Kurunegala, Gampaha, Kegalle, and Kandy districts, Sri Lanka.

\begin{tabular}{|c|c|c|c|c|c|c|c|c|c|}
\hline \multirow[b]{2}{*}{ Genera } & \multirow[b]{2}{*}{ Species name } & \multicolumn{2}{|r|}{ Kurunegala district } & \multicolumn{2}{|c|}{ Gampaha district } & \multicolumn{2}{|c|}{ Kegalle district } & \multicolumn{2}{|c|}{ Kandy district } \\
\hline & & $n$ & Relative abundance (\%) & $n$ & $\begin{array}{c}\text { Relative } \\
\text { abundance (\%) }\end{array}$ & $n$ & $\begin{array}{c}\text { Relative } \\
\text { abundance (\%) }\end{array}$ & $n$ & $\begin{array}{c}\text { Relative } \\
\text { abundance (\%) }\end{array}$ \\
\hline \multirow{2}{*}{ Aedes } & Ae. aegypti & 42 & 2.7 & 160 & 14.88 & 243 & 19.19 & 86 & 10.3 \\
\hline & Ae. albopictus & 183 & 11.78 & 276 & 26.38 & 176 & 13.9 & 306 & 36.65 \\
\hline \multirow{2}{*}{ Anopheles } & An. subpictus & 110 & 7.08 & 0 & 0 & 0 & 0 & 0 & 0 \\
\hline & An. vagus & 8 & 0.51 & 0 & 0 & 0 & 0 & 0 & 0 \\
\hline Armigeres & Armigeres sp. & 0 & 0 & 0 & 0 & 140 & 11.06 & 0 & 0 \\
\hline \multirow{7}{*}{ Culex } & Cx. quinquefasciatus & 236 & 15.19 & 215 & 20.34 & 235 & 18.56 & 113 & 13.53 \\
\hline & Cx. tritaeniorynchus & 394 & 25.35 & 180 & 16.87 & 197 & 15.56 & 161 & 19.28 \\
\hline & Cx. gelidus & 411 & 26.45 & 117 & 10.61 & 134 & 10.58 & 112 & 13.41 \\
\hline & Cx. whitmorei & 101 & 6.5 & 35 & 2.48 & 24 & 1.9 & 12 & 1.44 \\
\hline & Cx. fuscocephala & 12 & 0.77 & 38 & 2.78 & 0 & 0 & 0 & 0 \\
\hline & Cx. infula & 0 & 0 & 0 & 0 & 78 & 6.16 & 0 & 0 \\
\hline & Cx bitaeniorynchus & 0 & 0 & 18 & 0.79 & 0 & 0 & 0 & 0 \\
\hline Mansonia & Mansonia sp. & 10 & 0.64 & 22 & 1.19 & 0 & 0 & 0 & 0 \\
\hline Tripteroides & Tripteroides sp. & 47 & 3.02 & 47 & 3.68 & 21 & 1.66 & 45 & 5.39 \\
\hline Uranotaenia & Uranotaenia sp. & 0 & 0 & 0 & 0 & 18 & 1.42 & 0 & 0 \\
\hline \multicolumn{2}{|c|}{ Total mosquito larvae collected } & 1554 & & 1108 & & 1266 & & 835 & \\
\hline
\end{tabular}

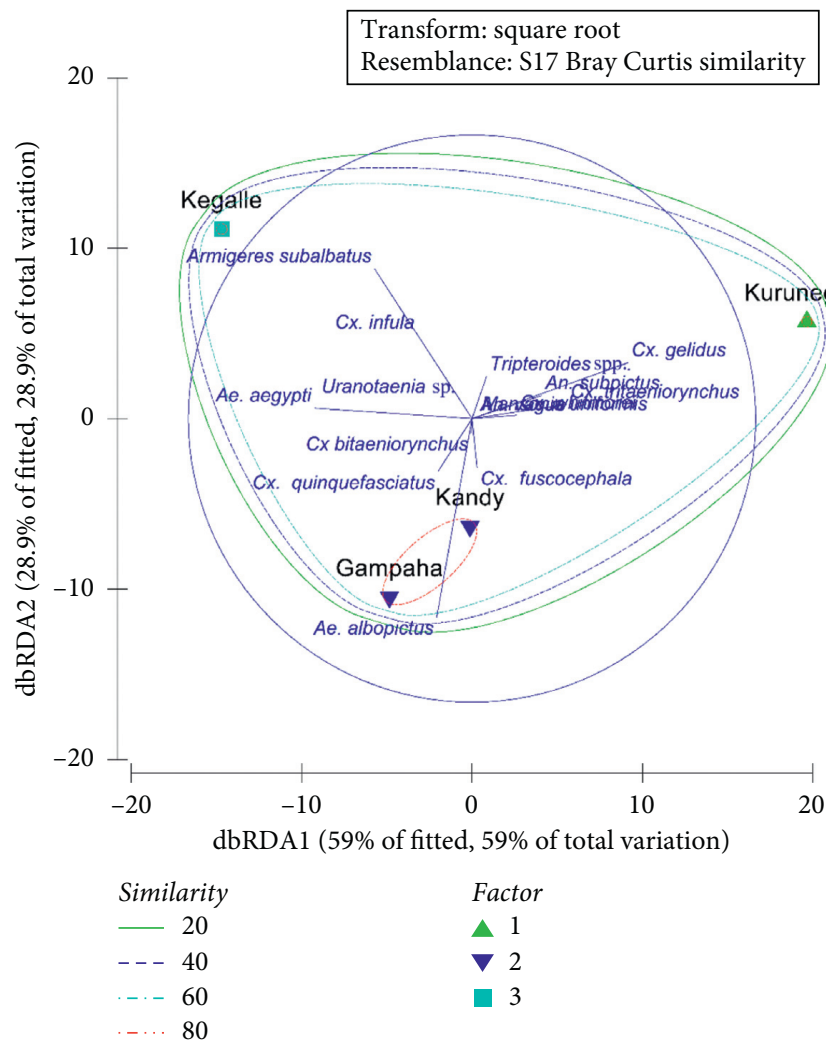

Figure 2: dbRDA plot for distribution of mosquito species in Kurunegala, Kegalle, Gampaha, and Kandy districts, Sri Lanka.

decades. The current vector surveillance system is not systematized, and there is no regular monitoring of vector abundance. Some control programs only target the specified vectors for that disease, and reporting of other vector species is ignored. Knowledge of where mosquitoes breed, their habitat preference over others, and the larval distribution are important parameters for risk assessment and sound mosquito control strategies [22].
Water-holding containers are found to be the main larval breeding habitats for Ae. aegypti and Ae. albopictus in all the four districts. Only outdoor sampling of dengue vector mosquitoes was performed in the present study; hence, no information on the breeding of the vector indoors could be determined. Anyhow, Chan et al. [23] have stated that the majority of the habitats of Ae. aegypti larvae are also found indoors such as earthenware jars, tin cans, 
TABLE 3: List of breeding habitats encountered in Kurunegala, Gampaha, Kegalle, and Kandy districts, Sri Lanka.

\begin{tabular}{|c|c|c|c|c|c|}
\hline \multirow{2}{*}{ Nature of habitat } & \multirow{2}{*}{ Breeding habitat $(n)$} & \multicolumn{4}{|c|}{ District } \\
\hline & & Kurunegala & Gampaha & Kegalle & Kandy \\
\hline \multirow{5}{*}{ Macro } & Paddy field (23) & + & + & + & + \\
\hline & Marshy land (12) & + & + & + & + \\
\hline & Reservoir (2) & + & - & - & - \\
\hline & Pond (6) & + & + & + & + \\
\hline & Tank margin (4) & + & + & - & - \\
\hline \multirow{16}{*}{ Micro } & Irrigation canal (13) & + & + & + & + \\
\hline & Blocked drain (10) & + & + & + & + \\
\hline & Tree hole (16) & + & + & + & + \\
\hline & Plastic container/barrel (13) & + & + & + & + \\
\hline & Burrow pit $(4)$ & + & + & - & - \\
\hline & Tire (6) & + & + & + & + \\
\hline & Leaf axil (5) & - & + & + & + \\
\hline & Rain gutter (3) & - & - & + & + \\
\hline & Metal container (15) & + & + & + & + \\
\hline & Glassware (3) & - & - & + & + \\
\hline & Coconut shell (7) & - & + & + & + \\
\hline & Leaf litter (5) & + & - & + & + \\
\hline & Clay pot (2) & + & - & - & - \\
\hline & Footprint (3) & + & + & - & - \\
\hline & Abandoned well (4) & - & + & + & + \\
\hline & Concrete slab (4) & - & + & + & + \\
\hline
\end{tabular}

Note: number of habitats sampled included in parentheses.

ant traps, rubber tires, bowls, and drums. The immature forms of Ae. albopictus were found in artificial containers with stagnant water besides natural habitats such as tree holes, rock holes, hollow bamboo stumps, and leaf axils [24], agreeing with findings of the current study. In Sri Lanka, dengue has become a significant socioeconomic and public health burden. Aedes aegypti is considered as the predominant vector, while Ae. albopictus is considered as a subsidiary vector of dengue in Sri Lanka. Although Ae. aegypti is considered as the primary or major vector of dengue [25], which initiate outbreaks and transmitting disease in highly urbanized areas, Aedes albopictus is also playing a significant role in transmitting dengue in suburban and rural areas [26].

Genus Culex indicated a diversified collection denoting seven species from all districts. Out of the seven reported species, three ( $C x$. tritaeniorynchus, $C x$, gelidus, and $C x$. fuscocephala) transmit Japanese encephalitis (JE) virus in Sri Lanka $[27,28]$. Also, Cx. quinquefasciatus, which is a major vector for filariasis, was collected from all districts. Therefore, this signifies the entomological potential to transmit JE and filariasis infections in these districts. However, Sri Lanka intends to maintain the success of eliminating $\mathrm{LF}$ as a public health problem and prevent its resurgence. A few "hot spots" remain in the country, which necessitates continued vigilance. In Sri Lanka, LF was endemic in eight districts (Colombo, Kalutara, Gampaha, Galle, Matara, Hambantota, Kurunegala, and Puttalam), and about half of the population of Sri Lanka live in filariasis endemic districts [29]. Therefore, regular entomological monitoring activities, elimination of breeding sites, and continued special and routine surveillance activities are instrumental in achieving the elimination of filariasis.
Sri Lanka, being a country in which a considerable extent of land is occupied by irrigation reservoirs and paddy fields, those permanent habitats have become ideal breeding habitats for many mosquitoes. Major epidemics of JE have also occurred associated with the rice fields in Sri Lanka [30]. A study conducted in the Kelaniya area in Gampaha district of Sri Lanka has indicated the presence of four Culex mosquitoes namely $C x$. gelidus, $C x$. tritaeniorynchus, $C x$. fuscocephala, and Cx. pseudovishnui from paddy fields [8]. Kurunegala district is an area with a higher abundance of rice fields and associated agricultural practices; thus, associated Culex mosquito abundance was found to be higher in those areas. Furthermore, rainfall patterns also may dilute the water in rice fields, altering their physicochemical properties, resulting in changes in larval density and species succession [31].

Kurunegala has been a malaria endemic district in Sri Lanka. Regardless of the few cases that have been reported from Kegalle and Kandy districts until the recent past, there were no indigenous cases identified from these districts, since 2012. The most recent indigenous cases have been identified from Kegalle, Kandy, Gampaha, and Kurunegala districts in 2009, 2010, 2010, and 2010, respectively [32-34]. The rapid influx of indigenous cases of malaria from foreign travelers has become a major challenge in the malaria prevention programs in Sri Lanka. In 2015, all 36 recorded cases of malaria were imported, with mortality being zero [35]. Classification of cases is based on information accruing from the rigorous case investigations, which are carried out on every case of malaria detected with a view of determining if there is a chance of the case being locally acquired. According to the available data at the Malaria campaign of Sri Lanka, during the last 2 years (2015-2016), 77 cases have 

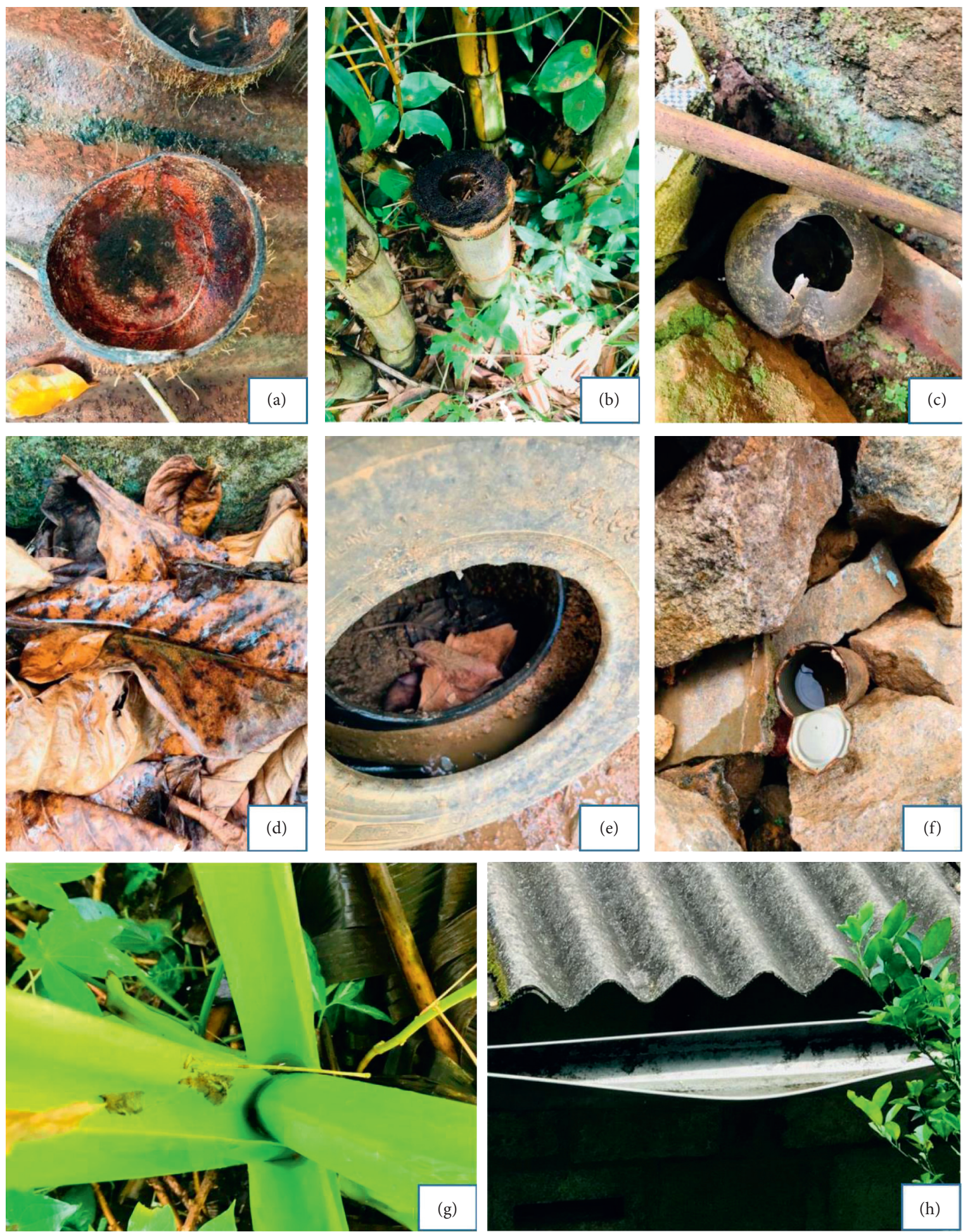

Figure 3: Immature mosquito habitats, (a) coconut shell, (b) bamboo tree hole, (c) clay pot, (d) leaf litter, (e) tire, (f) metal container, (g) leaf axil, and (h) roof gutter.

been reported, the majority of which have been reported from the Western Province (Colombo, Gampaha, and Kalutara districts) [35, 36].

In the present investigation, only An. subpictus and $A n$. vagus were identified from Kurunegala district, which was an early malaria endemic district in Sri Lanka. This may be due to the limited breeding habitats examined, and many of the breeding habitats investigated were temporary microbreeding habitats that may not be conducive for Anopheles. An ecological analysis of mosquitoes in rice fields conducted at Habaraluwewa area in Sri Lanka for 18 months revealed the presence of mosquitoes under genera Anopheles, Aedes, 


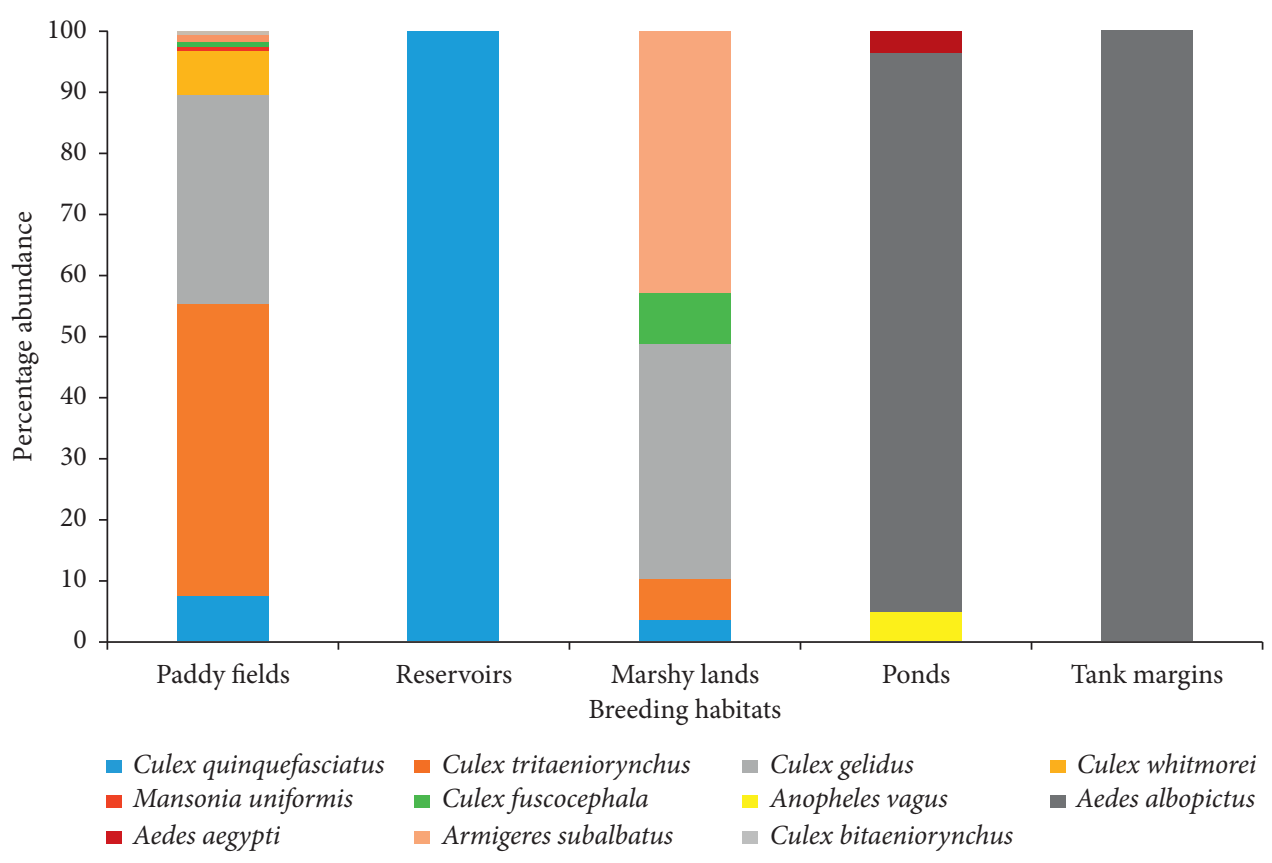

(a)

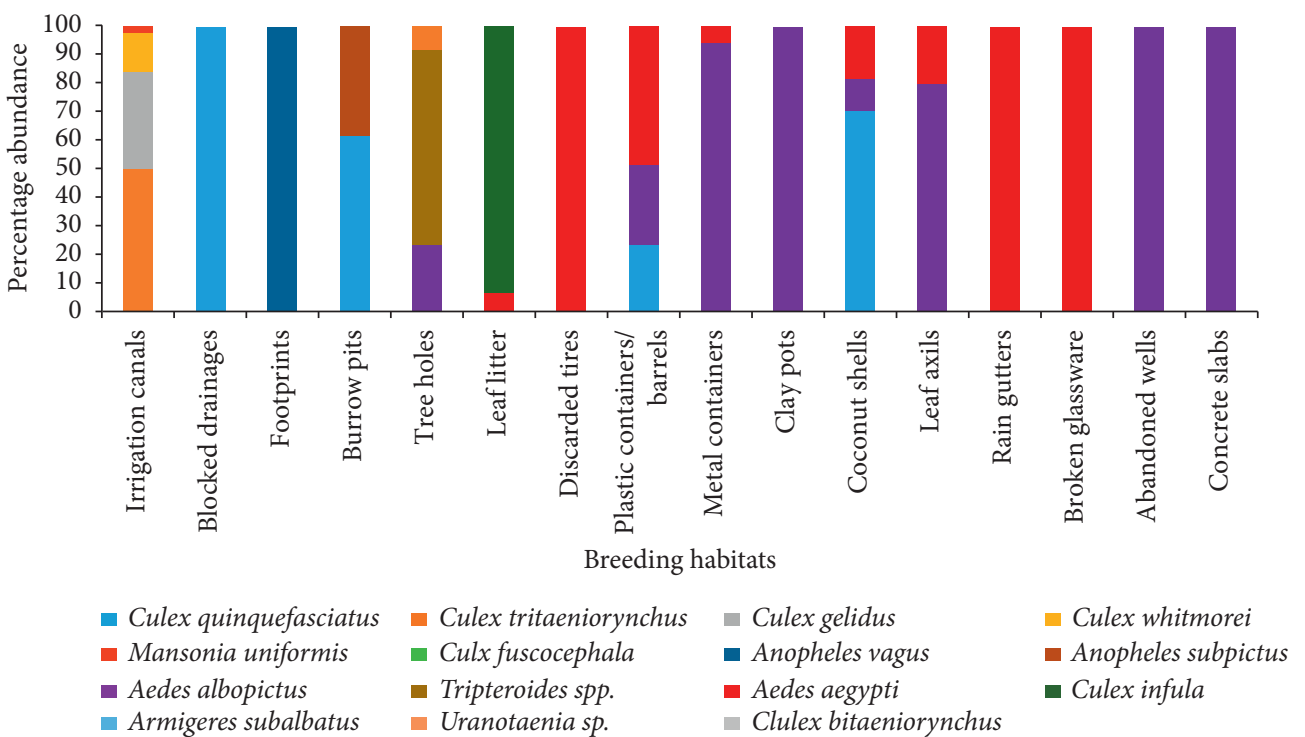

(b)

Figure 4: (a) The percentage abundance of mosquito species encountered in different macrobreeding habitats. (b) The percentage abundance of mosquito species encountered in different microbreeding habitats.

Mansonia, and Armigeres. Meanwhile, seepage pools and paddy fields were characterized with the highest density and occurrence of Anopheles and Culex species [28]. As well, six Culex species including $C x$. gelidus, Cx. tritaeniorynchus, and $C x$. fuscocephala, which are considered to be vectors for JE transmission in Sri Lanka [30, 37], were recorded from paddy fields and associated irrigation canals in the present study.

In the present study, the majority of $C x$. quinquefasciatus was recorded from blocked drains. Muturi [38] has stated that $C x$. quinquefasciatus prefers to breed in organically polluted water from the garbage-filled pools, ditches, and drains [39]. Unplanned urbanization in sampling areas had led to the increase of associated $C x$. quinquefasciatus vector populations in those areas. From marshy lands, $C x$. gelidus was sampled with a higher density. The presence of vegetation and floating plants provides optimal breeding conditions for Cx. gelidus by acting as food sources and shelter from predators [40], while vegetation creates stagnant conditions by decreasing water movements.

Mansonia species tend to lay eggs in vegetation-covered habitats, often on the under surfaces of floating leaves of aquatic plants [41]. Only Mansonia uniformis was recorded from the present investigation, which is considered to 
TABLE 4: The abundance of the immature stages of medically important mosquito species encountered in each breeding habitat.

\begin{tabular}{|c|c|c|c|c|c|c|}
\hline Genera & Species & Habitat type & Breeding habitat & Relative abundance & Immature stages $(n)$ & $\begin{array}{c}\text { Relative } \\
\text { abundance (\%) }\end{array}$ \\
\hline \multirow{20}{*}{ Aedes } & \multirow{9}{*}{ Ae. aegypti } & Macro & Pond & 6 & 6 & 0.14 \\
\hline & & \multirow{8}{*}{ Micro } & Plastic container/barrel & 41 & 290 & 6.74 \\
\hline & & & Leaf litter & 2 & 5 & 0.12 \\
\hline & & & Metal container & 4 & 22 & 0.51 \\
\hline & & & Roof gutter & 24 & 71 & 1.65 \\
\hline & & & Glassware & 38 & 38 & 0.88 \\
\hline & & & Leaf axil & 3 & 3 & 0.07 \\
\hline & & & Coconut shell & 13 & 26 & 0.60 \\
\hline & & & Tire & 9 & 56 & 1.30 \\
\hline & \multirow{11}{*}{ Ae. albopictus } & \multirow{2}{*}{ Macro } & Tank margin & 13 & 40 & 0.93 \\
\hline & & & Pond & 30 & 152 & 3.53 \\
\hline & & \multirow{9}{*}{ Micro } & Plastic container/barrel & 41 & 163 & 3.79 \\
\hline & & & Clay pot & 18 & 36 & 0.84 \\
\hline & & & Concrete tube & 17 & 68 & 1.58 \\
\hline & & & Tree hole & 10 & 51 & 1.19 \\
\hline & & & Glassware & 21 & 41 & 0.95 \\
\hline & & & Leaf axil & 3 & 12 & 0.28 \\
\hline & & & Coconut shell & 7 & 29 & 0.67 \\
\hline & & & Abandoned well & 4 & 14 & 0.33 \\
\hline & & & Metal container & 37 & 329 & 7.65 \\
\hline \multirow{2}{*}{ Anopheles } & An. subpictus & Micro & Burrow pit & 110 & 110 & 2.56 \\
\hline & An. vagus & Macro & Stream margin & 8 & 8 & 0.19 \\
\hline Armigeres & Armigeres sp. & Macro & Marshy land & 47 & 140 & 3.25 \\
\hline \multirow{15}{*}{ Culex } & \multirow{8}{*}{ Cx. quinquefasciatus } & \multirow{3}{*}{ Macro } & Marshy land & 12 & 12 & 0.28 \\
\hline & & & Reservoir & 42 & 84 & 1.95 \\
\hline & & & Paddy field & & 108 & 2.51 \\
\hline & & \multirow{4}{*}{ Micro } & Blocked drain & 19 & 185 & 4.30 \\
\hline & & & Plastic container & 68 & 135 & 3.14 \\
\hline & & & Coconut shell & 26 & 26 & 0.60 \\
\hline & & & Burrow pit & 58 & 173 & 4.02 \\
\hline & & \multirow{2}{*}{ Macro } & Paddy field & 56 & 676 & 15.71 \\
\hline & \multirow[t]{2}{*}{ Cx. tritaeniorynchus } & & Marshy land & 11 & 22 & 0.51 \\
\hline & & Micro & Irrigation canal & 41 & 224 & 5.21 \\
\hline & \multirow{3}{*}{ Cx. gelidus } & \multirow{2}{*}{ Macro } & Paddy field & 69 & 485 & 11.27 \\
\hline & & & Marshy land & 21 & 127 & 2.95 \\
\hline & & Micro & Irrigation canal & 38 & 152 & 3.53 \\
\hline & \multirow{2}{*}{ Cx. whitmorei } & Macro & Paddy field & 25 & 100 & 2.32 \\
\hline & & Micro & Irrigation canal & 21 & 62 & 1.44 \\
\hline \multirow{2}{*}{ Mansonia } & \multirow{2}{*}{ Mansonia spp. } & Macro & Paddy field & 10 & 10 & 0.23 \\
\hline & & Micro & Irrigation canal & 6 & 12 & 0.28 \\
\hline
\end{tabular}

transmit brugian filariasis [42]. The current study highlights the necessity of integrated vector control strategies focusing on the different categories of breeding sites without limiting to a specific vector of interest in a control program with the co-occurrence of different medically important mosquitoes in the same breeding habitats.

Irregular disposal of household waste products such as polythene and artificial containers are major contributory factors for the increment of mosquito breeding places in the study area, also increasing the potential risk for disease transmission by enhancing the vector receptivity. Also, unplanned urbanization and town development in the study area created additional risk for disease transmission by increasing the number of mosquito breeding grounds. Mosquito replacement in an area could be occurred due to environmental changes caused by urbanization in the form of increased mosquito breeding habitats. This has been confirmed by a survey carried out in Colombo district, Sri Lanka [43]. Therefore, regular surveillance activities are of ample importance to identify the entomological potential for disease transmission with time, and this investigation emphasizes the necessity of an integrated program to survey medically important mosquitoes in all districts, which may ultimately be useful for successful elimination of vectors.

Furthermore, this would ultimately provide an avenue to improve the personal skills of health staff rather than limiting their knowledge to specified disease vectors under which the control program is concerned. On the other hand, this approach would be a beneficial solution to the limited trained staff and funding through the rational use of finances and human resources to achieve better productivity and fruitfulness of such programs. Therefore, this warrants 
TABLe 5: Diversity of medically important mosquito species encountered in different breeding habitats across the four districts.

\begin{tabular}{|c|c|c|c|c|c|c|}
\hline Breeding site & Species richness & Shannon-Weiner index & Menhinik's index & Margalef's index & Pielou's index & Dominance \\
\hline Paddy field & $7^{\mathrm{a}}$ & $7.06 \pm 2.8^{\mathrm{a}}$ & $3.34 \pm 0.83^{\mathrm{a}}$ & $0.59 \pm 0.19^{\mathrm{a}}$ & $2.01 \pm 0.6^{\mathrm{a}}$ & $0.28 \pm 0.06^{\mathrm{a}}$ \\
\hline Reservoir & $1^{\mathrm{d}}$ & 0 & $0.03 \pm 0.01^{\mathrm{d}}$ & 0 & 0 & $0.01 \pm 0.00^{\mathrm{c}}$ \\
\hline Tank margin & $1^{\mathrm{d}}$ & $0.57 \pm 0.4^{\mathrm{c}}$ & $0.11 \pm 0.04^{\mathrm{d}}$ & $0.32 \pm 0.12^{\mathrm{b}}$ & $0.21 \pm 0.1^{\mathrm{c}}$ & $0.01 \pm 0.00^{\mathrm{c}}$ \\
\hline Marshy land & $5^{\mathrm{b}}$ & $1.52 \pm 0.5^{\mathrm{b}}$ & $1.50 \pm 0.26^{\mathrm{b}}$ & $0.32 \pm 0.09^{\mathrm{b}}$ & $0.52 \pm 0.2^{\mathrm{b}}$ & $0.06 \pm 0.02^{\mathrm{b}}$ \\
\hline Pond & $3^{\mathrm{c}}$ & 0 & $0.10 \pm 0.03^{\mathrm{d}}$ & $0.06 \pm 0.02^{\mathrm{d}}$ & 0 & $0.04 \pm 0.01^{c}$ \\
\hline Irrigation canal & $4^{\mathrm{b}}$ & $1.86 \pm 0.4^{\mathrm{b}}$ & $0.99 \pm 0.21^{\mathrm{b}}$ & $0.36 \pm 0.11^{\mathrm{b}}$ & $0.59 \pm 0.2^{\mathrm{b}}$ & $0.09 \pm 0.03^{b}$ \\
\hline Blocked drainage & $1^{\mathrm{d}}$ & 0 & $0.04 \pm 0.01^{\mathrm{d}}$ & $0.11 \pm 0.04^{\mathrm{d}}$ & 0 & $0.06 \pm 0.02^{\mathrm{b}}$ \\
\hline Burrow pit & $2^{c}$ & 0 & $0.02 \pm 0.01^{\mathrm{d}}$ & $0.02 \pm 0.01^{\mathrm{d}}$ & 0 & $0.06 \pm 0.01^{\mathrm{b}}$ \\
\hline Tree hole & $3^{c}$ & $1.56 \pm 0.3^{\mathrm{b}}$ & $0.83 \pm 0.26^{\mathrm{c}}$ & $0.38 \pm 0.09^{\mathrm{b}}$ & $0.59 \pm 0.1^{\mathrm{b}}$ & $0.05 \pm 0.01^{\mathrm{c}}$ \\
\hline Leaf litter & $2^{c}$ & 0 & $0.11 \pm 0.03^{\mathrm{d}}$ & $0.03 \pm 0.01^{\mathrm{d}}$ & 0 & $0.02 \pm 0.01^{\mathrm{c}}$ \\
\hline Tire & $1^{\mathrm{d}}$ & 0 & $0.11 \pm 0.02^{\mathrm{d}}$ & $0.10 \pm 0.04^{\mathrm{d}}$ & 0 & $0.01 \pm 0.00^{\mathrm{c}}$ \\
\hline Plastic container & $3^{c}$ & $1.56 \pm 0.6^{\mathrm{b}}$ & $1.02 \pm 0.32^{\mathrm{b}}$ & $0.13 \pm 0.05^{\mathrm{d}}$ & $0.48 \pm 0.1^{\mathrm{b}}$ & $0.12 \pm 0.04^{\mathrm{b}}$ \\
\hline Metal container & $2^{c}$ & 0 & $0.03 \pm 0.01^{\mathrm{d}}$ & $0.11 \pm 0.06^{\mathrm{d}}$ & 0 & $0.09 \pm 0.03^{\mathrm{b}}$ \\
\hline Clay pot & $1^{\mathrm{d}}$ & 0 & $0.04 \pm 0.01^{\mathrm{d}}$ & 0 & 0 & $0.01 \pm 0.00^{\mathrm{c}}$ \\
\hline Footprint & $1^{\mathrm{d}}$ & 0 & $0.12 \pm 0.02^{\mathrm{d}}$ & 0 & 0 & 0 \\
\hline Roof gutter & $1^{\mathrm{d}}$ & 0 & 0 & $0.09 \pm 0.03^{\mathrm{d}}$ & 0 & $0.02 \pm 0.00^{\mathrm{c}}$ \\
\hline Glassware & $1^{\mathrm{d}}$ & 0 & 0 & $0.08 \pm 0.02^{\mathrm{d}}$ & 0 & $0.02 \pm 0.00^{\mathrm{c}}$ \\
\hline Leaf axil & $2^{c}$ & 0 & 0 & $0.22 \pm 0.09^{c}$ & 0 & 0 \\
\hline Coconut shell & $3^{c}$ & $1.23 \pm 0.8^{\mathrm{b}}$ & $0.55 \pm 0.11^{\mathrm{c}}$ & $0.20 \pm 0.09^{c}$ & $0.47 \pm 0.2^{\mathrm{b}}$ & $0.02 \pm 0.00^{\mathrm{c}}$ \\
\hline Concrete slab & $1^{\mathrm{d}}$ & 0 & 0 & $0.09 \pm 0.03^{\mathrm{d}}$ & 0 & $0.02 \pm 0.01^{\mathrm{c}}$ \\
\hline Abandoned well & $1^{\mathrm{d}}$ & 0 & 0 & $0.07 \pm 0.02^{\mathrm{d}}$ & 0 & 0 \\
\hline
\end{tabular}

Note: different superscript letters in each column ( $a, b, c$, and d) denote significant variations suggested by the Kruskal-Wallis statistics at $95 \%$ of significance, followed by the Dunn test with Bonferroni adjustment as the post hoc test.

vector control entities to rethink of a countrywide integrated surveillance and control approach for medically important disease vectors.

\section{Conclusion}

Cx. gelidus was the most predominant mosquito species in Kurunegala followed by $C x$. tritaeniorynchus. Ae albopictus remained the most abundant mosquito species in Gampaha and Kegalle districts. Meanwhile, Ae. aegypti (19.19\%) dominated in Kegalle district. The presence of medically important mosquitoes in these areas in considerable numbers can cause public health concerns as dengue is one of the major challenges in these areas. Therefore, the study of this nature would be useful to identify the entomological potential for disease transmission, and updates would be facilitated for implementing appropriate vector control interventions.

\section{Data Availability}

The datasets supporting this study are included within the article. Data will not be shared in any of the sources.

\section{Conflicts of Interest}

The authors declare that they have no conflicts of interest.

\section{Authors' Contributions}

Koshila Ranasinghe conducted field surveys, performed data collection, and wrote the manuscript. Nayana Gunathilaka supervised and wrote the manuscript. Deepika Amarasinghe did conceptualization, funding acquisition, designed the study, and supervised the research. Lahiru Udayanga conducted the statistical analysis and wrote the manuscript. All authors read and approved the final manuscript.

\section{Acknowledgments}

The authors would like to thank the National Science Foundation, Sri Lanka (Grant No. RG/2017/EB/02), for their financial support for data collection.

\section{Supplementary Materials}

Annexure 1a: percentage abundance of different mosquito species within the Gampaha district. Annexure 1b: percentage abundance of different mosquito species within the Kandy district. Annexure 1c: percentage abundance of different mosquito species within the Kegalle district. Annexure 1d: percentage abundance of different mosquito species within the Kurunegala district. (Supplementary Materials)

\section{References}

[1] Disease Surveillance, List of Notifiable Diseases, Epidemiology Unit, Sri Lanka, http://www.epid.gov.lk/web/index.php?option= com_content\&view=article\&id=145\&Itemid=446\&lang=en.

[2] N. Gunathilaka, "Annotated checklist and review of the mosquito species (Diptera: Culicidae) in Sri Lanka," Journal of Insect Biodiversity, vol. 7, no. 3, pp. 38-50, 2018.

[3] Ministry of Health, Weekly Epidemiological Report, A Publication of the Epidemiology Unit, Ministry of Health, vol. 40, no. 21, Colombo, Sri Lanka, 2013.

[4] R. A. Varshini and M. Kanagappan, "Mosquito larval diversity in three rural areas of Kanyakumari District, Tamil Nadu," 
International Journal of Mosquito Research, vol. 2, no. 3, pp. 10-13, 2015.

[5] F. I. Aigbodion and M. A. Anyiwe, "Mosquitoes and environments: some economic costs of malaria in Nijeria," Nijerian Journal of Entomology, vol. 22, pp. 93-107, 2005.

[6] G. Aditya, M. K. Premanik, and G. K. Saha, "Larval habitats and species composition of mosquitoes in Darjeeling Himalayas, India," Journal of Vector Borne Diseases, vol. 43, pp. 7-15, 2006.

[7] L. Udayanga, N. Gunathilaka, M. C. M. Iqbal, U. S. AmarasingheLakmal, and W. Abeyewickreme, "Comprehensive evaluation of demographic, socio-economic and other associated risk factors affecting the occurrence of dengue incidence among Colombo and Kandy Districts of Sri Lanka: a cross- sectional study," Parasites \& Vectors, vol. 11, no. 1, p. 478, 2018.

[8] L. D. Amarasinghe and G. I. S. Weerakkodi, "Density and diversity of mosquito larvae associated with rice fields and marshland habitats in two climatically different areas in Sri Lanka," International Journal of Entomological Research, vol. 2, no. 2, pp. 59-71, 2014.

[9] C. M. Mutero, P. N. Ng'ang'a, P. Wekoyela, J. Githure, and F. Konradsen, "Ammonium sulphate fertilizer increases larval populations of Anopheles arabiensis and culicine mosquitoes in rice fields," Acta Tropica, vol. 89, no. 2, pp. 187-192, 2004.

[10] A. Eitam, L. Blaustein, and M. Mangel, "Effects of Anispos sardea on oviposition habitat selection by mosquitoes and other dipterans and on community structure in artificial pools," Hydrobiologia, vol. 485, no. 1/3, pp. 183-189, 2002.

[11] J. B. Z. Zahouli, K. Benjamin, P. Müller, D. Malone, T. Yao, and J. Utzinger, "Urbanization is a main driver for the larval ecology of Aedes mosquitoes in arbovirus-endemic settings in south-eastern Côte d'Ivoire," PLOS Neglected Tropical Diseases, vol. 11, no. 7, Article ID e0005751, 2017.

[12] B. Giovanni, C. Jeffries, and T. Walker, "Biological control of mosquito vectors: past, present, and future," Insects, vol. 7, no. 4, p. 52, 2016.

[13] W. Sun, L. Xue, and X. Xie, "Spatial-temporal distribution of dengue and climate characteristics for two clusters in Sri Lanka from 2012 to 2016," Scientific Reports, vol. 7, no. 1, Article ID 12884, 2017.

[14] M. W. Service, Mosquito Ecology- Field Sampling Methods, Springer, Dordrecht, Netherlands, 1993.

[15] F. Amerasinghe, "Illustrated keys to the genera of mosquitoes (Diptera: Culicidae) in Sri Lanka," Journal of the National Science Foundation of Sri Lanka, vol. 23, no. 4, pp. 183-211, 1995.

[16] N. Gunathilaka, "Illustrated keys to the adult female Anopheles (Diptera; Culicidae) mosquitoes of Sri Lanka," Applied Entomology and Zoology, vol. 52, no. 1, pp. 69-77, 2017.

[17] R. V. Chelliah, "Keys and illustrations to the genera of mosquitoes of Sri Lanka (Diptera: Culicidae)," Contributions of the American Entomological Institute, vol. 7, no. 4, pp. 1-84, 1984.

[18] N. Gunathilaka, T. Fernando, M. Hapugoda, W. Abeyewickreme, and R. Wickremasinghe, "Revised morphological identification key to the larval anophelene (Diptera: Culicidae) of Sri Lanka," Asian Pacific Journal of Tropical Biomedicine, vol. 4, no. 1, pp. S222-S227, 2017.

[19] S. H. Hurlbert, "A coefficient of interspecific assciation," Ecology, vol. 50, no. 1, pp. 1-9, 1969.

[20] L. Udayanga, N. Gunathilaka, M. C. Iqbal, M. M. Najim, K. Pahalagedara, and W. Abeyewickreme, "Empirical optimization of risk thresholds for dengue: an approach towards entomological management of Aedes mosquitoes based on larval indices in the Kandy District of Sri Lanka," Parasites \& Vectors, vol. 11, no. 1, p. 368, 2018.

[21] N. D. A. D. Wijegunawardana, Y. I. N. Gunawardene, T. G. A. N. Chandrasena, R. S. Dassanayake, N. W. B. A. L. Udayanga, and W. Abeyewickreme, "Evaluation of the effects of Aedes vector indices and climatic factors on dengue incidence in Gampaha District, Sri Lanka," BioMed Research International, vol. 2019, Article ID 2950216, 11 pages, 2019.

[22] WHO, Annual Report 2016, WHO, Colombo, Sri Lanka, 2016, http://www.searo.who.int/srilanka/documents/who_srl_annual_ report_2016.pdf.

[23] J. N. Ijumba and S. W. Lindsay, "Impact of irrigation on malaria in Africa: paddies paradox," Medical and Veterinary Entomology, vol. 15, no. 1, pp. 1-20, 2001.

[24] K. L. Chan, B. C. Ho, and Y. C. Chan, "Aedes aegypti (L) and Aedes albopictus (Skuse) in Singapore city," Bulletin of the World Health Organization, vol. 44, no. 5, pp. 629-633, 1971.

[25] W. Hawley, P. Reiter, R. Copeland, C. Pumpuni, and G. Craig Jr., "Aedes albopictus in North America: probable introduction in used tires from Northern Asia," Science, vol. 236, no. 4805, pp. 1114-1116, 1987.

[26] K. Rajesh, D. Dhanasekaran, and B. K. Tyagi, "Survey of container breeding mosquito larvae (dengue vector) in Tiruchirappalli district, Tamil Nadu, India," Journal of Entomology and Zoology Studies, vol. 1, no. 6, pp. 88-91, 2013.

[27] Y. Higa, "Dengue vectors and their spatial distribution," Tropical Medicine and Health, vol. 39, no. 4, pp. S17-S27, 2011.

[28] J. S. M. Peiris, L. P. Perera, C. K. Arunagiri, and F. P. Amerasinghe, "Arboviruses in Sri Lanka," in Proceedings of the First International Conference on the Impact of Viral Diseases on the Development of Asian Countries, p. 177, Bangkok, Thailand, December 1986.

[29] J. Yasuoka and R. Levins, "Ecology of vector mosquitoes in Sri Lanka-suggestions for future mosquito control in rice ecosystems," The Southeast Asian Journal of Tropical Medicine and Public Health, vol. 38, no. 4, pp. 646-657, 2007.

[30] Ministry of Health, Weekly Epidemiological Report, vol. 43, no. 4, A Publication of the Epidemiology Unit, Ministry of Health, Colombo, Sri Lanka, 2016, http://www.epid.gov.lk/ web/images/pdf/wer/2016/vol_43_no_04-english.pdf.

[31] J. S. M. Peiris, C. K. Amerasinghe, C. K. Arunagiri et al., "Japanese encephalitis in Sri Lanka: comparison of vectors and virus ecology in different agroclimatic areas," Transactions of the Royal Society of Tropical Medicine and Hygiene, vol. 87, no. 5, pp. 541-548, 1992.

[32] T. Ramachandra Rao, The Anophelines of India, ICMR, New Delhi, India, 1984.

[33] Ministry of Health, Epidemiological Bulletin, vol. 50, Ministry of Health, Colombo, Sri Lanka, Fourth Quarter, 2009, http://www.epid.gov.lk/web/attachments/article/ 166/Volume_50_4th_qtr_2009.pdf.

[34] Ministry of Health, Epidemiological Bulletin, vol. 52, Ministry of Health, Colombo, Sri Lanka, Second Quarter, 2010, http://www.epid.gov.lk/web/attachments/article/ 165/QEB\%202nd\%20Quarter\%202010\%20new.pdf.

[35] Ministry of Health, Epidemiological Bulletin, vol. 51, Ministry of Health, Colombo, Sri Lanka, First Quarter, 2010, http:// www.epid.gov.lk/web/attachments/article/165/Volume_51_ 1st_qtr_2010.pdf.

[36] Anti Malaria Campaign, Annual Report 2015, Anti Malaria Campaign, Colombo, Sri Lanka, 2015, http://www. malariacampaign.gov.lk/images/Publication\%20Repository/ Annual\%20Reports/Annual\%20Report\%202015.pdf. 
[37] Anti Malaria Campaign, Annual Report 2016, Anti Malaria Campaign, Colombo, Sri Lanka, 2016, http://www. malariacampaign.gov.lk/images/Publication\%20Repository/ Annual\%20Reports/Annual_Report_2016.pdf.

[38] F. P. Amerasinghe, J. S. M. Peiris, S. H. P. P. Karunarathne, and P. H. Amerasinghe, "Epidemiology of the 1987 Japanese encephalitis outbreak in the Anuradhapura area, entomological aspects," Proceedings of Sri Lanka Medical Association, vol. 101, pp. 22-23, 1998.

[39] E. J. Muturi, J. Mwangangi, J. Shililu et al., "Mosquito species succession and physicochemical factors affecting their abundance in rice fields in Mwea, Kenya," Journal of Medical Entomology, vol. 44, no. 2, pp. 336-344, 2007.

[40] M. Hasegawa, V. S. Nam, N. Tuno, M. Takagi, and N. T. Yen, "Influence of the distribution of host species on adult abundance of Japanese encephalitis vectors Culex vishnui subgroup and Culex gelidus in a rice-cultivating village in Northern Vietnam," The American Journal of Tropical Medicine and Hygiene, vol. 78, no. 1, pp. 159-168, 2008.

[41] P. Yadav, "Factors affecting mosquito populations in created wetlands," vol. 1, pp. 1-43, Environmental Science Graduate Program of the Ohio State University, Columbus, OH, USA, 2009, Thesis.

[42] J. Day, "Mosquito oviposition behavior and vector control," Insects, vol. 7, no. 4, p. 65, 2016.

[43] C. H. Mallawarachchi, T. G. A. Nilmini Chandrasena, R. Premaratna, S. M. N. S. M. Mallawarachchi, and N. R. de Silva, "Human infection with sub-periodic Brugia spp. in Gampaha District, Sri Lanka: a threat to filariasis elimination status," Parasites Vectors, vol. 11, no. 1, p. 68, 2018.

[44] B. A. S. Priyangika, B. G. D. N. K. De Silva, D. P. W. JayathungaKatuwawalage, and M. B. Wickramasinghe, "The association of environmental changes and the replacement of mosquito fauna in the Colombo District, Sri Lanka," Journal of Tropical Forestry and Environment, vol. 4, no. 1, pp. 59-66, 2014. 